\title{
Dissatisfaction with residency: A discrepancy between preferences and expectations?
}

\author{
LOURDES BIEDMA-VELÁZQUEZ, RAFAEL SERRANO-DEL-ROSAL, JOSÉ M. GARCÍA-DE-DIEGO \\ \& JOSÉ A. CERRILLO-VIDAL \\ Instituto de Estudios Sociales Avanzados, Spain
}

\begin{abstract}
Background: Medical residents play two roles that enter into conflict during their educational period: trainees and workers. This dual role can lead to dissatisfaction among residents that can affect both the quality of the services they provide to citizens and the proper functioning of the health services model itself.

Aim: To analyse discrepancies between the preferences and expectations of first-year medical residents and whether these differences affect satisfaction with the residency.

Method: A questionnaire was administered on-line to the entire population of first-year medical residents of the Autonomous Community of Andalusia (Spain) in 2008. We performed a means contrast test between the indicator discrepancy (difference between preferences and expectations during the residency as a training or a working period), overall satisfaction with the residency and their relationship to other expectations of medical residents.

Results: Respondents showing greater discrepancy have a more negative opinion about the residency.

Conclusion: There is a gap between what residents prefer and what they expect from the residency, giving rise to dissatisfaction. This gap must be bridged to improve the quality of training received by these new physicians, their satisfaction and hence the delivery of health services to citizens.
\end{abstract}

\section{Introduction}

The public health system of Spain is a universal and free system for all citizens. As a result, it is the largest employer of physicians, providing employment to more than $90 \%$ of all medical school graduates. The public health system has full jurisdiction over residents' training and attaches great importance to educating them not only to acquire the knowledge, attitudes, clinical skills and methods of their profession, but also in understanding the model of healthcare and services they aspire to deliver: its values, working dynamics and ultimately, its internal functioning and objectives.

However, residents encounter significant differences between the education they receive during their college years and the values that the public health system attempts to instil in them during the residency period. These discrepancies are largely due to the fact that the educational system is structured around the teaching of theoretical knowledge chiefly through lectures aimed at abstract concepts and reflective observation, while residency focuses on learning through practice and clinical experience (concrete experience and active experimentation) (Kolb 1984; Armstrong \& ParsaParsi 2005; Borraci et al. 2008). These are two forms of professional socialisation that influence how the resident performs in the medical profession (Delani \& Bragge 2009). These differences between teaching styles give rise to unfulfilled expectations and dissatisfaction among residents, who must adapt to a new way of learning where the notion of

\section{Practice points}

- During their training, residents perform two roles: that of student and that of worker. However, they perform duties with similar responsibilities as medical professionals.

- A conflict between these two roles (trainee and worker) arises among residents due to the discrepancy between their preferences and expectations regarding the residency.

- Residents showing the greatest discrepancies between preferences and expectations are also more dissatisfied with the residency period.

- Healthcare managers must rethink the residency training model to ensure that the residents do not equate themselves to a 'cheap workforce'. By doing so, the residents will perceive that the residency is truly a training period.

education and labour are often undistinguishable from one another as revealed in a qualitative study conducted by our research group (Serrano et al. 2009). The study demonstrated that the dual nature of residencies as a period of training and work was a major source of dissatisfaction among a group of medical residents in Andalusia, who came to define themselves as 'cheap labour'. 
This negative vision among residents is a source of concern for the public health system, which is not oblivious to the fact that individuals who are satisfied with their professional activity are more effective and deliver higher quality care (European Foundation for Quality Management 1999). Resident satisfaction is also an issue of concern as it is an indicator of the occupational health of these professionals, particularly in terms of what is known as the 'burnout syndrome' (Freudenberger 1974; Maslach \& Jackson 1978). Health professionals are more prone to stress than other professionals, with residents being one of the most vulnerable groups (Schwartz et al. 1987; Smith 2001a; Tomas 2004; Prins et al. 2007). In addition, it has been found that fatigue, anxiety and dissatisfaction among residents in training increases the likelihood of medical errors (Jagsi et al. 2005; West et al. 2006).

The conflicting roles of residents as both students and professionals lead to what is known as 'training stress' due to the imbalances between training, labour and clinical aspects of the residency. In the words of the residents, 'you come to a site where the medical care is not linked to your training, although there is a sign on the door of the hospital that says Teaching Hospital. This simply means that there are people in the hospital receiving less money for doing the same job as others do' (Serrano et al. 2009: 50), 'I can see that the medical care is covered with cheap labour' (Serrano et al. 2009: 48). The residential system is designed theoretically as learning based on the accomplishment of practical tasks, but this system gives rise to conflicts because it is not clear whether the resident should be training or working.

To examine these conflicting roles and their effect on the satisfaction of medical residents, we analyse the preferences and expectations of these health professionals. When residents begin their training, they have certain desires or preferences regarding the residency (Thompson \& Suñol 1995). Although these preferences have an effect on residents' expectations, they should not be confused with them. Expectations refer to what an individual expects to find in both positive and negative terms. They are the mental image that one has of a given service and are determined by different factors, such as prior experience, collective discourse, preconceived notions and culture (Steiber \& Krowinski 1990; Mira et al. 2000). When preferences are consistent with expectations, individuals have a positive attitude towards the system being evaluated.

In this article, we analyse the discrepancies between what residents prefer and what they expect from medical residencies with regard to their dual role as trainee and employee during this period. Satisfaction depends on how individuals resolve the conflict (or cognitive dissonance) arising from discrepancies between their preferences and expectations (what we call discrepancy) and what they actually encounter in the residency (Festinger 1957). Several studies have been carried out on the satisfaction of health professionals (Smith 2001b) and medical residents (Ríos et al. 2004; Delani \& Bragge 2009) to determine which factors cause greater dissatisfaction, but few have focused on the expectations of these professionals and how such expectations influence their satisfaction (Artells \& Martínez 1995).

On the basis of this perspective, the aim of this study is to analyse discrepancies between the preferences and e2 expectations of first-year residents in Andalusia (Spain) regarding the nature of medical residencies as a period of training or work and to determine if these differences have an influence on satisfaction with the residency.

\section{Methods}

The data for this study were drawn from the survey 'Satisfaction and expectations of bealth professionals in training in the Andalusian Public Health System'. The survey was conducted in 2008 (E-0817) by the Institute for Advanced Social Studies of the Spanish National Research Council under a collaboration agreement with the Regional Ministry of Health of the Government of Andalusia (Spain). Data for the survey were collected by sending a link to an online questionnaire that was hosted on a web server. The link was sent to 924 medical residents who had initiated their training period (R1) in a teaching hospital of the Autonomous Community of Andalusia. A total of 578 residents responded to the survey (62.5\% of the population) following five reminders (four via e-mail to their corporate and/or individual e-mail addresses and one via a text message to their mobile phones) as established in the research design protocol.

The survey was divided into different blocks that included, among others, an assessment by first-year residents of their university education, their expectations regarding the medical residency that they had just initiated and their views on various aspects of the residency as well as on the public health system in general.

In this article, we focus on the expectations and preferences of the respondents with regard to their dual role as trainees and workers during the residency. These questions were formulated by means of a continuous status bar where 'only training' appeared at one end and 'only work' appeared at the other to mark the semantic differences between the two concepts. When responding, the residents placed the cursor at any point on the bar, which contained 500 possible points that the respondents could only differentiate visually, but not quantitatively (Figure 1).

These two variables were used to create a new indicator for measuring discrepancies between the residents' preferences and expectations, that is, a function of the distance between questions $p 31$ and $p 32$ in absolute values $(y=f|a-b|)$. This new indicator was assigned a minimum theoretical value of 0 when respondents believed that the residency would be in consonance with their preferences and a maximum theoretical value of 500 if the respondents thought the residency would be in complete dissonance with their preferences. Negative and positive signs were not taken into account. Hence, the direction of the discrepancy (towards training or towards work) had a null effect. The direction of the discrepancy was not taken into account as we were interested in determining the differences and similarities between the residents' preferences and expectations. A value of 50 and another of -50 indicate the same discrepancy between preferences and expectations. A positive value indicates that the residency has a higher training component than expected, while a negative value indicates that the residency involves a greater workload than expected. In both cases, the dissonance 


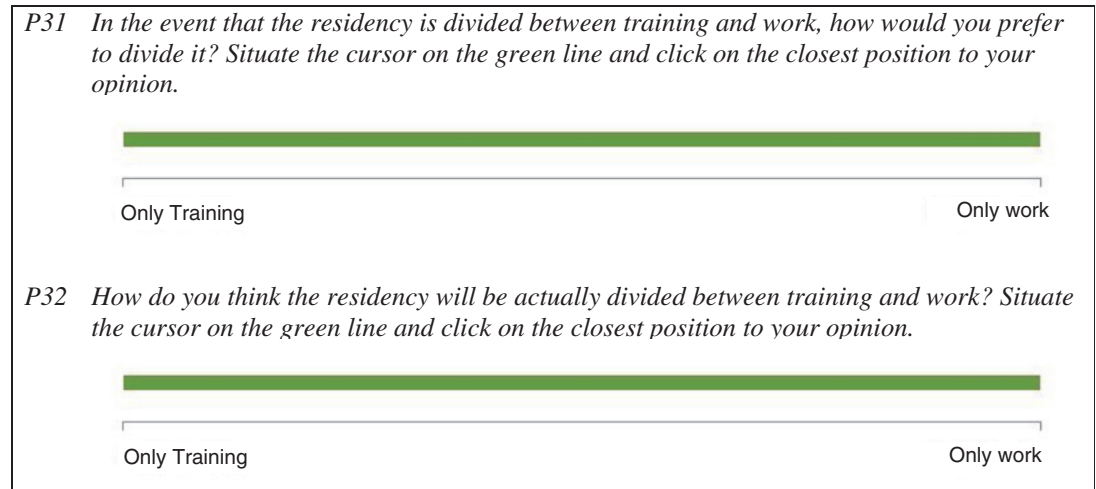

Figure 1. Questions P31 (preferences) and P32 (expectations).

Source: study E0817 IESA-CSIC.

between preferences and expectations is of equal quantity or proportion.

Following the creation of this new variable, which we call discrepancies, a means contrast test was performed to determine whether the difference between residents' preferences and expectations influences their first impressions of the residency, their expectations regarding increasing degrees of responsibility, their perception of equal opportunities, the ease with which they are able to combine the residency with other training activities and the extent to which they believe that they will encounter problems during the residency.

\section{Results}

As noted above, 578 residents responded to the survey, twothirds of whom were women (a proportion which is almost identical to that of the sample population). The respondents were young, with around half under the age of 26. Almost all of the residents were from Andalusia (86.8\%) or other regions of Spain $(6.8 \%)$, while only $6.4 \%$ were of a nationality other than Spanish (Table 1). The population is relatively homogeneous in terms of its socio-demographic characteristics. Specifically, the respondents are young, single (72\%), university graduates, and in the half the cases combine their residency with doctoral courses of study. Due to the abovementioned homogeneity, we have not found important differences regarding socio-demographic variables.

Overall, the first-year residents stated that they would like their duties to be equally distributed between training and work (av: 217.01, SD: 89.34). However, they believe that the residency will be more oriented towards work rather than training (av: 324.57, SD: 92.69) (Figure 2).

The mean value of the discrepancy indicator (i.e. the distance between residents' preferences and expectations in absolute values) is 133.69 with a standard deviation of 108.497 . If we consider the value of 250 to be at the midpoint of the scale, we find that nearly $84 \%$ of the evaluations made by the residents fall in the first interval (up to 250 points), while the second interval accounts for less than $13 \%$. In other words, although there are discrepancies between the preferences and expectations of residents, they are concentrated in the lower interval and are not important.
Table 1. Characteristics of residents.

\begin{tabular}{|c|c|c|c|}
\hline & & Frequency & Percentage \\
\hline \multirow[t]{2}{*}{ Sex } & Male & 197 & 34.08 \\
\hline & Female & 381 & 65.92 \\
\hline \multirow[t]{4}{*}{ Age groups } & Under 26 years & 234 & 40.48 \\
\hline & 26 to 29 years & 203 & 35.12 \\
\hline & Over 29 years & 124 & 21.45 \\
\hline & NA & 17 & 2.94 \\
\hline \multirow[t]{5}{*}{ Marital status } & Single & 416 & 71.97 \\
\hline & Married & 71 & 12.28 \\
\hline & Cohabiting & 71 & 12.28 \\
\hline & Separated or divorced & 3 & 0.52 \\
\hline & NA & 17 & 2.94 \\
\hline \multirow[t]{6}{*}{ People at home } & Alone & 126 & 21.80 \\
\hline & Share flat & 87 & 15.05 \\
\hline & With partner and/or children & 163 & 28.20 \\
\hline & With parents & 175 & 30.28 \\
\hline & Others & 10 & 1.73 \\
\hline & NA & 17 & 2.94 \\
\hline \multirow[t]{3}{*}{ Nationality } & Spanish & 525 & 90.83 \\
\hline & Others & 36 & 6.23 \\
\hline & NA & 17 & 2.94 \\
\hline \multirow[t]{3}{*}{ Specialty } & $\begin{array}{l}\text { Family, internal and } \\
\text { paediatrics medicine }\end{array}$ & 240 & 41.52 \\
\hline & Other medical specialities & 336 & 58.13 \\
\hline & NA & 2 & 0.35 \\
\hline \multirow{4}{*}{ PhD courses } & Yes & 232 & 40.14 \\
\hline & I am not doing & 290 & 50.17 \\
\hline & $\begin{array}{l}\text { No, I have already } \\
\text { done and finished }\end{array}$ & 53 & 9.17 \\
\hline & NA & 3 & 0.52 \\
\hline
\end{tabular}

Source: study E0817 IESA-CSIC.

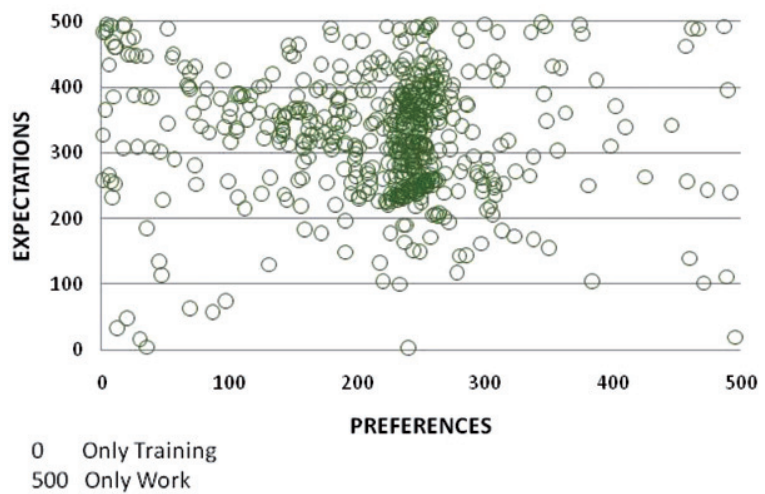

Figure 2. Graph of dispersion between the questions P31 (preferences) and questions P32 (expectations). Source: study E0817 IESA-CSIC. 
Table 2. The first impression and expectations of residents according to the indicator 'discrepancy' (difference between preferences and expectations during the residency as a training or a working period).

\begin{tabular}{|c|c|c|c|c|c|c|}
\hline Expectations & Frequency (\%) & Mean & $N$ & SD & $F$ & Sig. \\
\hline \multicolumn{7}{|c|}{ P26. What was your first impression of the residency? } \\
\hline Very negative/negative & 3.8 & 197.68 & 22 & 71.94 & & \\
\hline Neither negative nor positive & 12.0 & 162.83 & 66 & 106.72 & & \\
\hline Positive/very positive & 84.2 & 126.08 & 468 & 108.60 & & \\
\hline Total & 100 & 133.60 & 556 & 108.47 & 7.532 & 0.001 \\
\hline \multicolumn{7}{|c|}{ P28.3. I will gradually assume responsibilities during my residency } \\
\hline Disagree & 12.0 & 174.72 & 67 & 112.03 & & \\
\hline Neither agree nor disagree & 12.8 & 153.95 & 74 & 106.30 & & \\
\hline Agree & 75.2 & 123.33 & 415 & 106.41 & & \\
\hline Total & 100 & 133.60 & 556 & 108.46 & 8.184 & 0.000 \\
\hline \multicolumn{7}{|c|}{ P28.6. All the residents have equal training opportunities } \\
\hline Disagree & 58.6 & 144.42 & 324 & 108.07 & & \\
\hline Neither agree nor disagree & 21.9 & 115.39 & 123 & 102.45 & & \\
\hline Agree & 19.5 & 120.91 & 108 & 113.13 & & \\
\hline Total & 100 & 133.41 & 555 & 108.47 & 4.131 & 0.017 \\
\hline \multicolumn{7}{|c|}{ P30. Do you believe that it will be easy for you to combine your residency with the following activities? } \\
\hline \multicolumn{7}{|c|}{ P30.1. Scientific activities and thesis } \\
\hline Little or no possibility & 33.9 & 162.30 & 191 & 116.76 & & \\
\hline Neither often nor little & 41.4 & 124.36 & 232 & 101.45 & & \\
\hline Often or very often & 24.7 & 107.93 & 132 & 99.43 & & \\
\hline Total & 100 & 133.41 & 555 & 108.54 & 11.638 & 0.000 \\
\hline \multicolumn{7}{|c|}{ P30.2. Attendance to courses and conferences } \\
\hline Little or no possibility & 19.7 & 167.35 & 110 & 110.83 & & \\
\hline Neither often nor little & 39.5 & 133.77 & 222 & 109.11 & & \\
\hline Often or very often & 40.9 & 116.57 & 223 & 103.26 & & \\
\hline Total & 100 & 133.41 & 555 & 108.54 & 8.275 & 0.000 \\
\hline \multicolumn{7}{|c|}{ P30.3. Publication of scientific works } \\
\hline Little or no possibility & 27.2 & 168.08 & 154 & 120.20 & & \\
\hline Neither often nor little & 40.1 & 130.33 & 223 & 102.41 & & \\
\hline Often or very often & 32.8 & 108.18 & 177 & 97.44 & & \\
\hline Total & 100 & 133.74 & 554 & 108.50 & 13.303 & 0.000 \\
\hline \multicolumn{7}{|c|}{ P36. Of the items listed below, which do you think you will encounter during your residency? } \\
\hline \multicolumn{7}{|c|}{ P36.1. Work overload, long working hours and double shifts } \\
\hline Never/little & 8.2 & 101.36 & 45 & 105.34 & & \\
\hline Neither often nor little & 22.3 & 117.41 & 123 & 103.37 & & \\
\hline Often or very often & 69.6 & 142.34 & 387 & 108.38 & & \\
\hline Total & 100 & 133.41 & 555 & 107.77 & 4,736 & 0.009 \\
\hline \multicolumn{7}{|c|}{ P36.2. Responsibilities and duties superior to those of a first-year resident } \\
\hline Never/little & 12.5 & 96.12 & 68 & 85.37 & & \\
\hline Neither often nor little & 17.6 & 103.25 & 95 & 101.74 & & \\
\hline Often or very often & 69.9 & 147.30 & 392 & 109.83 & & \\
\hline Total & 100 & 133.41 & 555 & 107.77 & 11.465 & 0.000 \\
\hline \multicolumn{7}{|l|}{ P36.3. Boredom/monotony } \\
\hline Never/little & 59.3 & 121.42 & 328 & 104.59 & & \\
\hline Neither often nor little & 29.0 & 138.57 & 161 & 107.54 & & \\
\hline Often or very often & 11.7 & 181.11 & 66 & 111.31 & & \\
\hline Total & 100 & 133.41 & 555 & 107.77 & 8.927 & 0.000 \\
\hline
\end{tabular}

Source: study E0817 IESA-CSIC.

Moreover, the first impressions of residents are, in general, quite positive (Table 2). These percentages are quite similar to those found in previous studies (Leigh et al. 2002). At the beginning of the residency, medical residents appear to have expectations and are not wholly dissatisfied, but become disappointed and dissatisfied with the residency throughout the residency period. Respondents who have a negative impression of the residency also show higher scores on the discrepancy indicator, specifically 64.4 points above the mean. However, the discrepancy value is only 7.2 points below the midpoint among those with a positive view of the residency (Figure 3). That is, residents who have a positive view (the majority) are closer to the mean of the discrepancy e4 variable, while those with a negative opinion of the residency show a significantly higher discrepancy.

The variables that present significant discrepancies and summarise the different aspects that were measured on the questionnaire are shown in Table 2.

We observed that residents who have a more negative view of the residency, particularly with regard to the ease with which the residency can be combined with other training activities or possible problems in the workplace, also show greater discrepancies between their preferences and expectations. A difference of about 50 points was found between residents with a more positive view and those who have a more negative view for most of the indicators. The two 


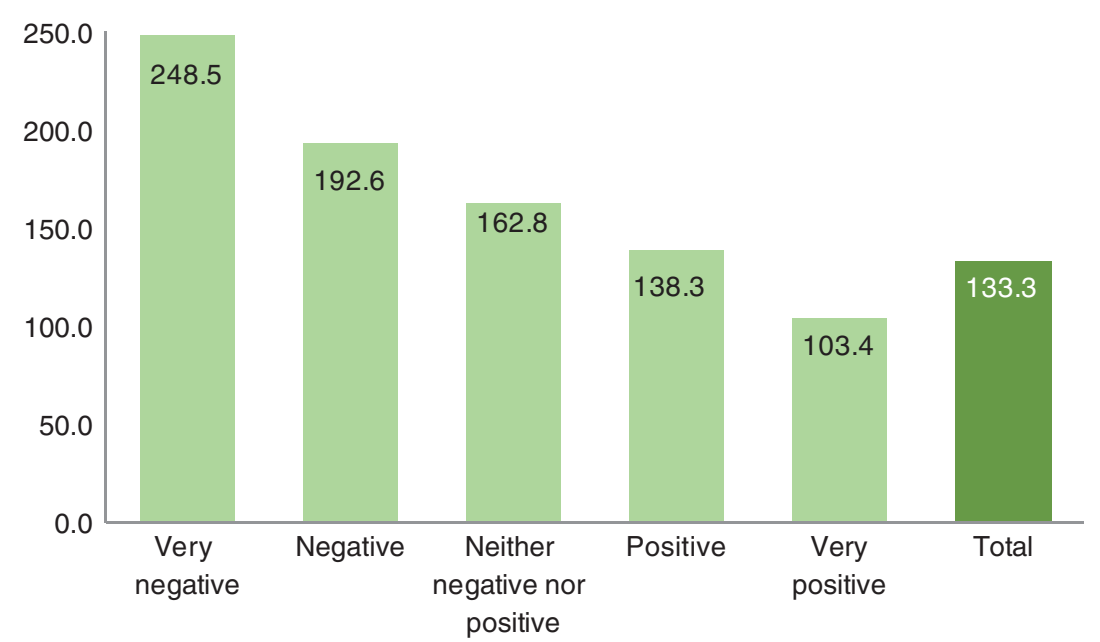

Figure 3. The first impression of the residency: discrepancy between preferences and expectations. Source: study E0817 IESA-CSIC.

indicators with the greatest differences (around 60 points) are the expectation of being able to publish a scientific paper during the residency (a greater discrepancy was found between those who believe they have 'little or no possibility' of publishing a paper) and the expectation that they will encounter boring and monotonous situations during the residency (a greater discrepancy was observed between respondents who believe they will encounter these situations 'often or very often').

\section{Discussion}

The residency training system in Spain (known as the MIR) has been praised by numerous professionals (Pijoán et al. 2001; Ríos et al. 2004), who have witnessed enormous improvements in the quality of the training of health professionals since the system was first implemented more than 25 years ago. However, many studies have also highlighted the fact that certain aspects of the MIR learning scheme cause dissatisfaction among residents (Blasco 2004; Borraci et al. 2008).

As we have shown in this study, the discrepancy between residents' preferences and expectations is related to negative views of the residency. But are the residents' preferences reasonable? Should the residency training system address these preferences? What aspects of the education or health system paradigm should be changed? Our objective here is not to question whether the residency should be primarily training oriented, work oriented or somewhere between the two as these issues are best left to the scholars and managers of these residency programmes. Insofar as what concerns us here, we have shown that there is a gap between what residents would like (their preferences) and what they believe or expect the residency to involve (Prins et al. 2010). In the words of the medical residents themselves cited from a study conducted in 1998 on this topic, 'our expectations are not fulfilled and this gives rise to the initial dissatisfaction' (García et al. 1998). As we have shown in this article, the residents prefer a residency period in which training and work are distributed in an equal manner (50-50\%). However, they expect that this will not be the case and that the residency will instead involve more work-related activities than actual training. This finding suggests that the residents may be dissatisfied with this aspect of the residency as they believe that the reality of the residency will not match their preferences.

In light of these results, we believe that the health administration must take account of the views and opinions of residents through a bidirectional evaluation of the residency period (American Board of Internal Medicine 1999) to improve the system. Indeed, despite its well-deserved prestige, there are many aspects of the system that are clearly in need of improvement (Gómez 2006), particularly given the changes occurring in society that have led to the formation of new values and new healthcare needs that professionals must be prepared to deal with. One of the aspects that is most in need of change is the harmonisation of university training schemes and those implemented in the health system itself. Consequently, greater coordination is needed between university training programmes and residency training programmes. If these two spheres of training do not converge, it will be impossible to resolve the conflicting roles of residents revealed in this article.

We encourage resident training managers to recommend synchronising university training and resident training schemes (the degree and the specialisation). In doing so, it is important to identify aspects that can lead to dissatisfaction among health professionals with a view to preventing conflicts that may cause anxiety among residents, not only to improve the wellbeing and occupational health of these professionals (a very important aspect no doubt) but also for the health and welfare of citizens in general, who at some point of their lives will be users of the health system. Citizen satisfaction is a good measure of the quality of health services and the satisfaction of the professionals who deliver them is key to achieving this quality.

For these reasons, it is necessary to reorient residency training schemes towards a 'learner-centred' approach that takes into account residents' expectations and preferences (Ricarte-Díez \& Martínez-Carretero 2008). At the same time, residents must adapt to the organisation that they have begun to form part of; an organisation in which users occupy a 
central role. Changing from an illness-centred model, and hence a healthcare professional-centred model, to a wellnessor user-oriented model for which physicians have not been prepared would clearly lead to dissonance between the two spheres in which training is provided: the university and the health system. Breaking this pattern will be the task of the institutions involved. In line with our analysis, we believe that it is necessary to change the current healthcare training model. This new model must ensure that resident training schemes are both sustainable and highly valued by the health professionals involved in them.

To conclude, it is necessary to highlight the main limitation of this study: the response rate. Although the response rates to the survey were similar to those found in other studies (Gosling et al. 2004) of this kind, caution should be taken with regard to the possible biasing effect of no response on the results. However, it is difficult to determine whether no responses are due to particular attitudes towards residential training or to other circumstances. Another limitation of the study is that we did not obtain responses from residents who had already completed their training period.

\section{Acknowledgements}

We thank Julia Ranchal, Sergio Galiano and Juan Antonio Dominguez for their insightful comments, suggestions and general support. We also thank the medical residents who kindly answered the survey, without whom this study would have been impossible.

\section{Ethical approval}

This study was carried out in compliance with Spanish Law 12/89 on Public Statistics. The project was submitted to the Ethics and Good Practices Committee and the Scientific and Technical Committee for Quality in Research of the IESA/CSIC.

Declaration of interest: The authors report no conflicts of interest. The authors alone are responsible for the content and writing of this article. The project (the databases that have been used in the study) was funded by the Regional Ministry of Health of the Government of Andalusia (Spain). All usual caveats apply.

\section{Notes on contributors}

Lourdes Biedma-Velázquez, BSc, is a Senior Technical Researcher at the Institute for Advanced Social Studies of the Spanish National Research Council. Her main research interests include welfare policy, the sociology of health and social research methods.

Rafael Serrano-Del-Rosal, PhD, is a Research Scientist of Health Sociology and Publics Policy of the Spanish National Research Council. He led the research line on subjective well-being, satisfaction and evaluation of public policy at the Institute for Advanced Social Studies. He is a member of the advisory committee of the International Journal of Sociology and of the editorial board of the journal Survey Methodology.

José M. García-De-Diego, BSc, is a Senior Research Technician at the Institute for Advanced Social Studies of the Spanish National Research Council.
His research focuses on the sociology of health, specifically issues such as satisfaction and expectations.

José A. CerRILlo-VIDAL, MSSc, is a Social Research Technician at the Institute for Advanced Social Studies of the Spanish National Research Council, and a PhD candidate at the Spanish Open University (UNED).

\section{References}

American Board of Internal Medicine. 1999. Guide to evaluation of resident in Internal Medicine. ABIM. Philadelphia, Pa. pp 1-15.

Armstrong E, Parsa-Parsi R. 2005. How can physicians' learning styles drive educational planning? Acad Med 80:680-684

Artells JJ, Martínez JA. 1995. Estudio prospectivo Delphi sobre perfil, actitudes, valores y expectativas de los profesionales de atención primaria en el siglo XXI. Cuadernos Gestión 5(Suppl. 1):1-124.

Blasco FJ. 2004. Insatisfacción de los médicos internos residentes. Med Clin (Barc) 123:157-158.

Borraci R, Guthman G, Rubio M, Arribalzaga EB. 2008. Estilos de aprendizaje en estudiantes universitarios y médicos residentes [Learning styles in university students and medical residents]. Educ Med 11(4):229-238.

Delani C, Bragge P. 2009. A study of physiotherapy student's and clinical educators' perception of learning and teaching. Med Teach 31:e402-e411.

European Foundation for Quality Management. 1999. Modelo Europeo de Excelencia. Madrid: Club Gestión de Calidad.

Festinger L. 1957. A theory of cognitive dissonance. Evanston, IL: Row and Peterson.

Freudenberger HJ. 1974. Staff burnout. J Soc Iss 30:159-165.

García M, Pérez C, Abós T, Expósito C. 1998. Residentes insatisfechos ¿Por qué? Semergen 24(4):301-302.

Gómez M. 2006. Transmisión de los valores médicos en la Universidad. Educ Med 9(Suppl. 1):44-48.

Gosling SD, Vazire S, Srivastava S, John OP. 2004. Should we trust webbased studies? A comparative analysis of six preconceptions about internet questionnaires. Am Psychol 59(2):93-104.

Jagsi R, Kitch BT, Weinstein DF, Campbell EG, Hutter M, Weissman JS. 2005. Residents report on adverse events and their causes. Arch Intern Med 165:2607-2613.

Kolb D. 1984. Experiential learning: Experience as the source of learning and development. Englewood Cliffs, NJ: Prentice-Hall, PTR.

Leigh JP, Kravitz RL, Schembi M, Samuels SJ, Mobley BS. 2002. Physician career satisfaction across specialties. Arch Intern Med 162:1577-1583.

Maslach C, Jackson S. 1978. Lawyer burnout. Barrister 5:52-54.

Mira JJ, Rodríguez J, Tirado S, Sitges E. 2000. Semejanzas y diferencias entre satisfacción y calidad percibida. Rev Calidad Asistencial 15:36-42.

Pijoán J, Urkaregi A, Morán JM. 2001. Evaluación por los médicos internos residentes de la formación recibida en los servicios hospitalarios: Una herramienta de monitorización. [Residents' assessment of education received in hospital departments: A monitoring tool]. Gac Sanit 15(5):432-440.

Prins JT, Gazendam-Donofrio SM, Tubben BJ, Van Der Heijden F, Van De Wiel H, Hoekstra-Weebers J. 2007. Burnout in medical residents: A review. Med Educ 41(8):788-800.

Prins JT, Hoekstra-Weebers J, Gazendam-Donofrio SM, Dillingh GS, Bakker AB, Huisman M, Jacobs B, Van Der Heijden F. 2010. Burnout and engagement among resident doctors in the Netherlands: A national study. Med Educ 44(3):236-247.

Ricarte-Díez J, Martínez-Carretero J. 2008. Formación del residente desde su abordaje como adulto. Educ Med 11(3):131-138.

Ríos A, Sánchez F, González L, Guerrero M. 2004. Research training during medical residency (MIR). Satisfaction questionnaire. Rev Esp Enferm Dig 96(10):695-704.

-Schwartz AJ, Black ER, Goldstein MG, Jozefowicz RF, Emmings FG. 1987. Levels and causes of stress among residents. Med Educ 62:744-753.

Serrano R, Cerrillo JA, Biedma L, López I, Ramírez A. 2009. La formación en el Sistema Sanitario Público de Andalucía I. Un análisis sociológico cualitativo. Sevilla: Consejería de Salud de la Junta de Andalucía. 
Smith R. 2001a. Why are doctors so unhappy? There are probably many causes, some of then deep. BMJ 322:1073-1074

Smith R. (ed.). 2001b. Why are doctors so unhappy? BMJ 322:1082-1083.

Steiber R, Krowinski J. 1990. Measuring and managing patient satisfaction. Chicago, IL: American Hospital Pub.

Thomas NK. 2004. Resident burnout. JAMA 292:2880-2889.
Thompson A, Suñol R. 1995. Expectations as determinants of patient satisfaction: Concept, theory and evidence. Int J Qual Health Care $7(2): 127-141$.

West CP, Huschka MM, Novotny PJ, Sloan JA, Kolars JC, Habermann TM, Shanafelt TD. 2006. Association of perceived medial errors with resident distress and empathy. A prospective longitudinal study. JAMA 269(9):1071-1078. 